\title{
Double-barrel Free Fibula for Segmental Defect of Ulna and Radius: Case Report
}

\section{Satyaswarup Tripathy}

PGIMER: Post Graduate Institute of Medical Education and Research

Jerry R John

PGIMER: Post Graduate Institute of Medical Education and Research

Mayank Mangal ( $\nabla$ mayank.mangal08@gmail.com )

PGIMER: Post Graduate Institute of Medical Education and Research https://orcid.org/0000-00032630-7310

\section{Research Article}

Keywords: Case report, double barrel free fibula, radius and ulna bone loss

Posted Date: May 7th, 2021

DOl: https://doi.org/10.21203/rs.3.rs-498229/v1

License: (c) (i) This work is licensed under a Creative Commons Attribution 4.0 International License. Read Full License

Version of Record: A version of this preprint was published at SN Comprehensive Clinical Medicine on July 9th, 2021. See the published version at https://doi.org/10.1007/s42399-021-01013-z. 
Title - DOUBLE-BARREL FREE FIBULA FOR SEGMENTAL DEFECT OF ULNA AND RADIUS: CASE REPORT.

\section{Authors -}

1. Dr. Satya Swarup Tripathy, M.S., M.ch., Additional professor, Department of plastic Surgery, PGIMER, Chandigarh. (Email - dr.sstripathy@gmail.com)

2. Dr. Jerry R. John, M.S., M.ch., Associate professor, Department of plastic Surgery, PGIMER, Chandigarh. (Email - jerryrjohn@ hotmail.com)

3. Dr. Mayank Mangal, M.S., M.ch., Senior resident, Department of plastic Surgery, PGIMER, Chandigarh. (E-mail - mayank.mangal08@gmail.com)

\section{Address of correspondence -}

Dr. Mayank Mangal, M.S., M.ch.

Senior Resident

Department of plastic surgery,

PGIMER, Chandigarh

E-mail - mayank.mangal08@gmail.com

Ph. No. - +919543775475 


\title{
Keywords
}

Case report, double barrel free fibula, radius and ulna bone loss

\begin{abstract}
Introduction - Post traumatic complex defects of the forearm require multiple operations and prolonged rehabilitation. Segmental bony defects of the radius and ulna are occasionally seen as part of these complex wounds. There are a few options in bridging the skeletal defect. These include corticocancellous bone grafting, creation of a one bone forearm and vascularised fibula. Vascularised bone grafting is superior in an ischemic and fibrosed area as it enhances local blood supply. The fibula is usually used to bridge the defect in one bone i.e. the radius.
\end{abstract}

Case presentation - A young male presented with an open comminuted fracture of radius and ulna following a crush injury to the left upper limb. The reconstruction was done in two stages - first a pedicled thoracoumbilical flap for soft tissue and in later stage a double barrel free fibula flap for segmental bone loss.

Conclusion - The above approach offered the best chance of skeletal healing in a complex defect. The patient was able to gain reasonably good upper extremity function with the described technique.

\section{Introduction}

Massive crush injury over the forearm may result in segmental bone loss in addition to composite soft tissue loss. Early wound closure with secondary bony reconstruction is the standard of care in such patients. There are a few surgical options to bridge the bone defect and to avoid non union. These include corticocancellous bone grafting, creation of a one bone 
forearm and vascularised bone grafting. In the last option, the blood supply of the grafted bone is maintained, right from the time of its placement into the defect. Biologically, vascularised bone grafting seems to be the best means to optimise union (1). However, literature has not provided convincing evidence favouring this option.

We present a patient who sustained crush injury over the proximal forearm in whom this plan was carried out.

\section{Case Presentation}

A young male presented with crush injury over the left forearm following road side accident. He had an open fracture of the proximal third of radius and ulna. Both bones over their proximal thirds were comminuted. The flexor musculature over the proximal forearm was also non-viable. Both the radial and ulnar pulses were palpable, and of good volume. Sensations over the median and ulnar territories were preserved, but not over the radial territory. The elbow had to be stabilised with a transarticular fixator along with an ulnar nail. In the emergency, the soft tissue was temporarily covered with a split skin graft (Figure 1). Further, this was replaced with a pedicled thoracoumbilical flap (Figure 2). The flap served the purpose of providing stable soft tissue over the area of crush, so that further bony reconstruction could proceed.

Secondarily, the segmental gap over the forearm (Figure 3) was bridged with a vascularised free fibular bone graft. At the time of the bony reconstruction, all wounds had healed and there was no local infection. The defect in the proximal radius measured $3 \mathrm{cms}$ and in the proximal ulna measured $3.5 \mathrm{cms}$. We harvested an osteoseptocutaneous fibular graft from the right leg. The entire length of the bone excluding $6 \mathrm{cms}$ of the upper end and $6 \mathrm{cms}$ of the lower end was taken. Fifteen cms of fibula was harvested. Three osteotomies were placed on 
the fibula. The proximal osteotomy shortened the length of the graft by $3 \mathrm{cms}$. This in turn, increased the length of the vascular pedicle. Two distal osteotomies were performed, $5.5 \mathrm{~cm}$ apart, to remove a central segment of the fibula (Figure 4). After the osteotomies, two bone grafts $3.5 \mathrm{cms}$ and $3 \mathrm{cms}$ long, remained attached to the vascular pedicle. These two grafts were positioned as intercalary grafts into the ulnar and radial defects.

The remaining two segments were plated to the ulna and the radius using four $2.0 \mathrm{~mm}$ titanium miniplates, each having four holes. Increasing the length of the vascular pedicle facilitated anastomosis of the vessels. The peroneal artery was anastomosed end to end with the proximal ulnar artery. The peroneal vein was anastomosed to the basilic vein. A skin island, $6 \mathrm{~cm}$ long and $2.5 \mathrm{cms}$ wide, was taken from the lateral aspect of the leg and used for postoperative monitoring. The ulnar nail was removed intraoperatively and the elbow was splinted in 90 degrees of flexion with a long arm cast.

The cast was removed six weeks after surgery. Range of motion exercises could be started, initially with elbow support and then, actively. One year after surgery, a bone scan revealed high uptake in the proximal forearm, confirming the increased local blood supply (Figure 5). Bony union was confirmed with plain radiographs (Figure 6).

Two years and four months after the injury, the patient uses his left hand for activities of daily life (Figure 7), and for fine activities like typing on a keyboard. Active ROM at the elbow was 70 degrees (from $10^{\circ}$ of elbow flexion to $80^{\circ}$ ). Active ROM at the wrist was 60 degrees (from neutral position to $60^{\circ}$ of wrist extension). He is extremely satisfied with his hand function. He is able to hold several objects, like a phone, a couple of books, a glass full of water and a one litre soft-drink bottle. The DASH score at the last follow up was 14. Also, there was no donor site morbidity in the leg. 


\section{Conclusion}

There are many methods described for reconstruction of segmental defects of the forearm. That some form of bone grafting is required is an unambiguous fact. Multiple reports describe the use of iliac crest autograft in between both the defects (Nicoll's technique). However, nonvascularised bone grafts require a well vascularised bed to survive. Union can take months and may not occur at all. Ring et al (2) concluded that high rates of union can be expected with cancellous bone grafting when the overlying scarring is limited and soft tissue compliant. It must be noted that the average segmental bone defect in their series was $2.2 \mathrm{cms}$. Faldini et al (3) reported good outcomes in atrophic non unions (average defect length-2cms) treated with non-vascular cortical strut fibular grafts. In comparison, vascularised bone grafts transport viable bone and osteocytes to the site of fracture. Callus formation and its ossification receive fresh impetus in this method. Possibly, larger defects can be bridged. Further, several reports discuss the creation of a one-bone forearm by uniting the radius to the ulna. Other authors have achieved union of only one bone (either radius or ulna) by means of the vascularised fibula $(4,5)$.

There are only limited numbers of reports which describe a double barrel fibula for reconstruction of segmental defects of both bones. However, this could be the best option out of the lot, considering restitution of the normal bony anatomy as well as optimisation of chances of union. Jones et al first reported the use of double barrel fibula for forearm reconstruction (6). This was followed by similar work in isolated cases by others (7-9). Our technique of double barrelling of the fibula was similar to Saint Cyr et al (10). In contrast to our case, they have used this option in two patients having infected non-union of the forearm. Moreover, fixation of the graft was achieved with lag screws alone or with the use of a locking compression plate. 
To conclude, crush forearm with segmental bony defects of both bones is a devastating injury which would warrant multiple surgical interventions. Bony union is most often achieved secondarily. A double barrel free fibular vascularised graft enhances local blood supply and encourages skeletal union. However, no extensive study exists, which proves the benefit of this procedure over others.

\section{Declarations}

Funding: None

Conflict of interest: None.

Ethical approval: No ethical issues are present in the publication of this report to the best of our knowledge.

Consent to participate and publication: The patient provided his consent to the publication of this report.

Availability of data and material - Not applicable

Code availability - Not applicable

Authors' Contribution - Dr. Jerry R John was the chief surgeon for the case and contributed in formulating the manuscript. Dr. Satya Swarup Tripathy was the senior surgeon for the case and contributed in the proof reading of manuscript. Dr. Mayank Mangal contributed in compiling the manuscript and submission. 


\section{References}

1. Heitmann C, Levin LS. Applications of the vascularized fibula for upper extremity reconstruction. Tech Hand Up Extrem Surg. 2003 Mar;7(1):12-7.

2. Ring D, Allende C, Jafarnia K, Allende BT, Jupiter JB. Ununited diaphyseal forearm fractures with segmental defects: Plate fixation and autogenous cancellous bone-grafting. J Bone Joint Surg Am, 2004 Nov;86(11):2440-5.

3. Faldini C, Pagkrati S, Nanni M, Menachem S, Giannini S. Aseptic forearm nonunions treated by plate and opposite fibular autograft strut. Clin Orthop Relat Res. 2009 Aug; 467(8): 2125-34.

4. Safoury Y. Free vascularized fibula for the treatment of traumatic bone defects and nonunion of the forearm bones. J Hand Surg Br. 2005 Feb;30(1):67-72.

5. Kumar VP, Satku K, Helm R, Pho RW. Radial reconstruction in segmental defects of both forearm bones. J Bone Joint Surg Br. 1988 Nov;70(5):815-7.

6. Jones NF, Swartz WM, Mears DC, Jupiter JB, Grossman A. The "double barrel" free vascularized fibular bone graft. Plast Reconstr Surg. 1988 Mar;81(3):378-85.

7. Santanelli F, Latini C, Leanza L, Scuderi N. Combined radius and ulna reconstruction with a free fibula transfer. Br J Plast Surg. 1996 Apr;49(3):178-82.

8. Yajima H, Tamai S, Ono H, Kizaki K, Yamauchi T. Free vascularized fibula grafts in surgery of the upper limb. J Reconstr Microsurg. 1999 Oct;15(7):515-21.

9. Zhen P, Liu XY, Li XS. Simultaneous radius and ulna reconstruction with folded free vascularized fibula transfer: case report. J Hand Surg Am. 2010 Jan;35(1):72-6. 
10. Saint-Cyr M, Farkas J, Gupta A. Double-barrel free fibula flap for treatment of infected non-union of both forearm bones. J Reconstr Microsurg. 2008 Nov;24(8):583-7. 


\section{Figures}

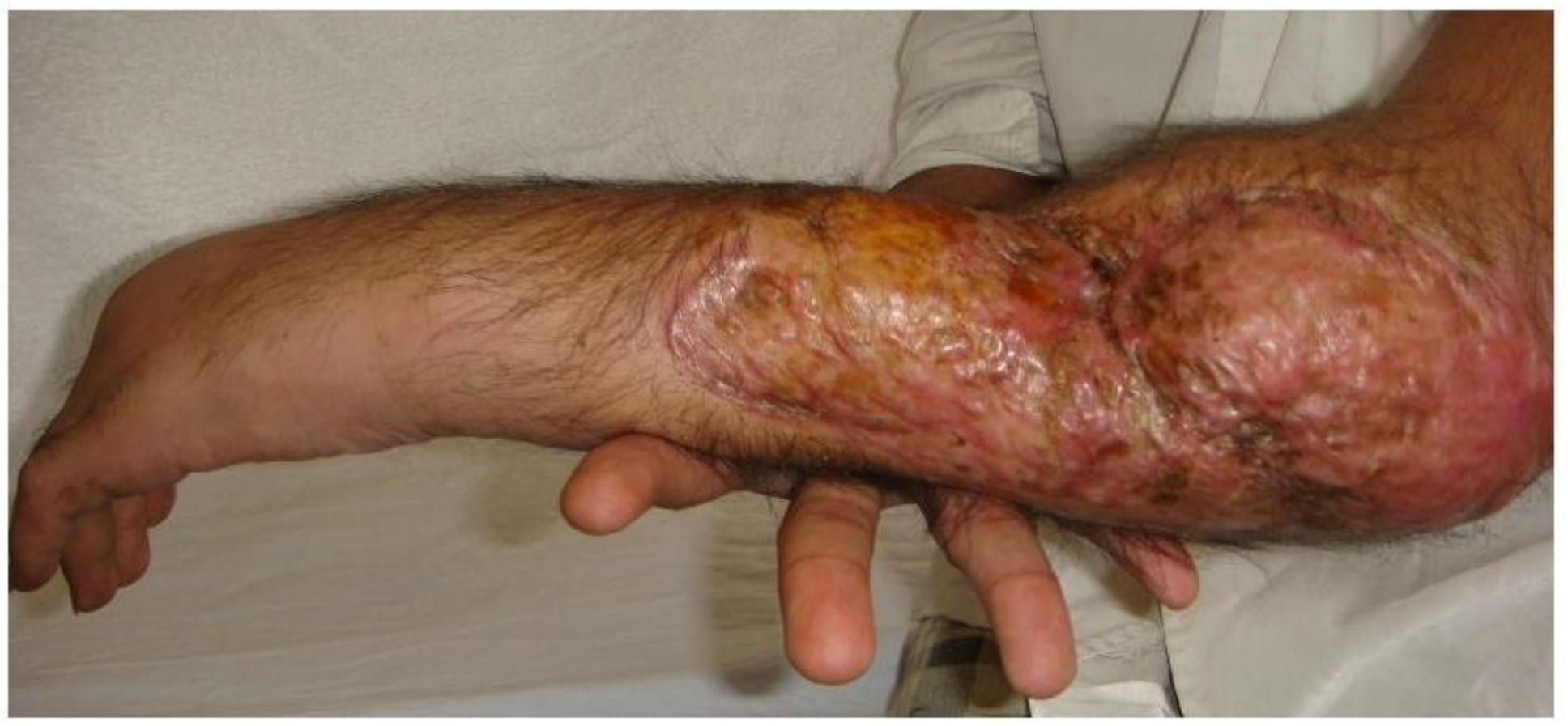

\section{Figure 1}

Initial picture of the left forearm shows the temporary skin graft cover over the wound. The external fixator has been removed, leaving an ulnar nail in the forearm. The patient is supporting this limb with the other hand.

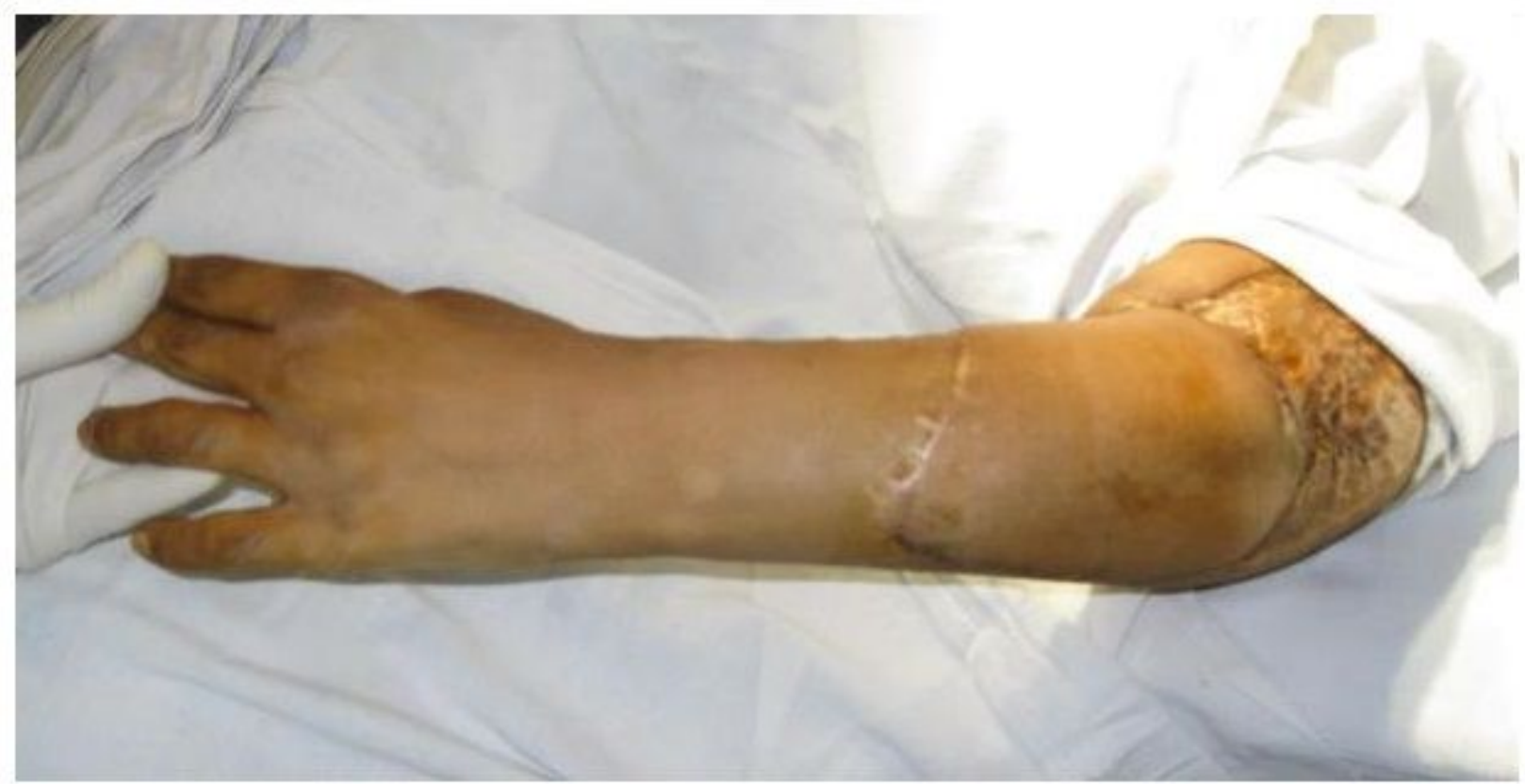

\section{Figure 2}

Picture shows the forearm after the soft tissue reconstruction with a pedicled thoracoumbilical flap cover. 


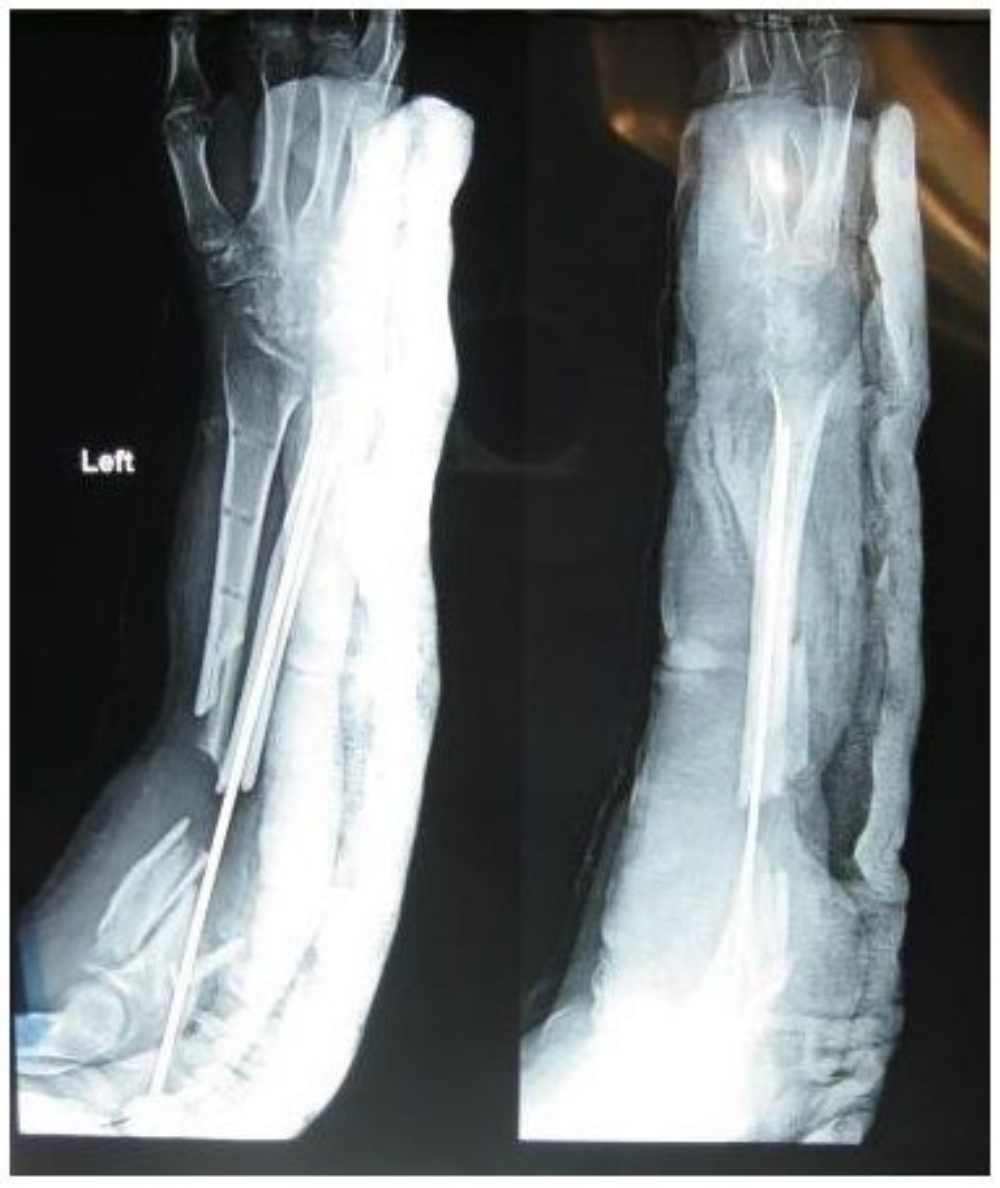

Figure 3

Xray of the forearm showing the bony defects. The ulnar nail is in situ.

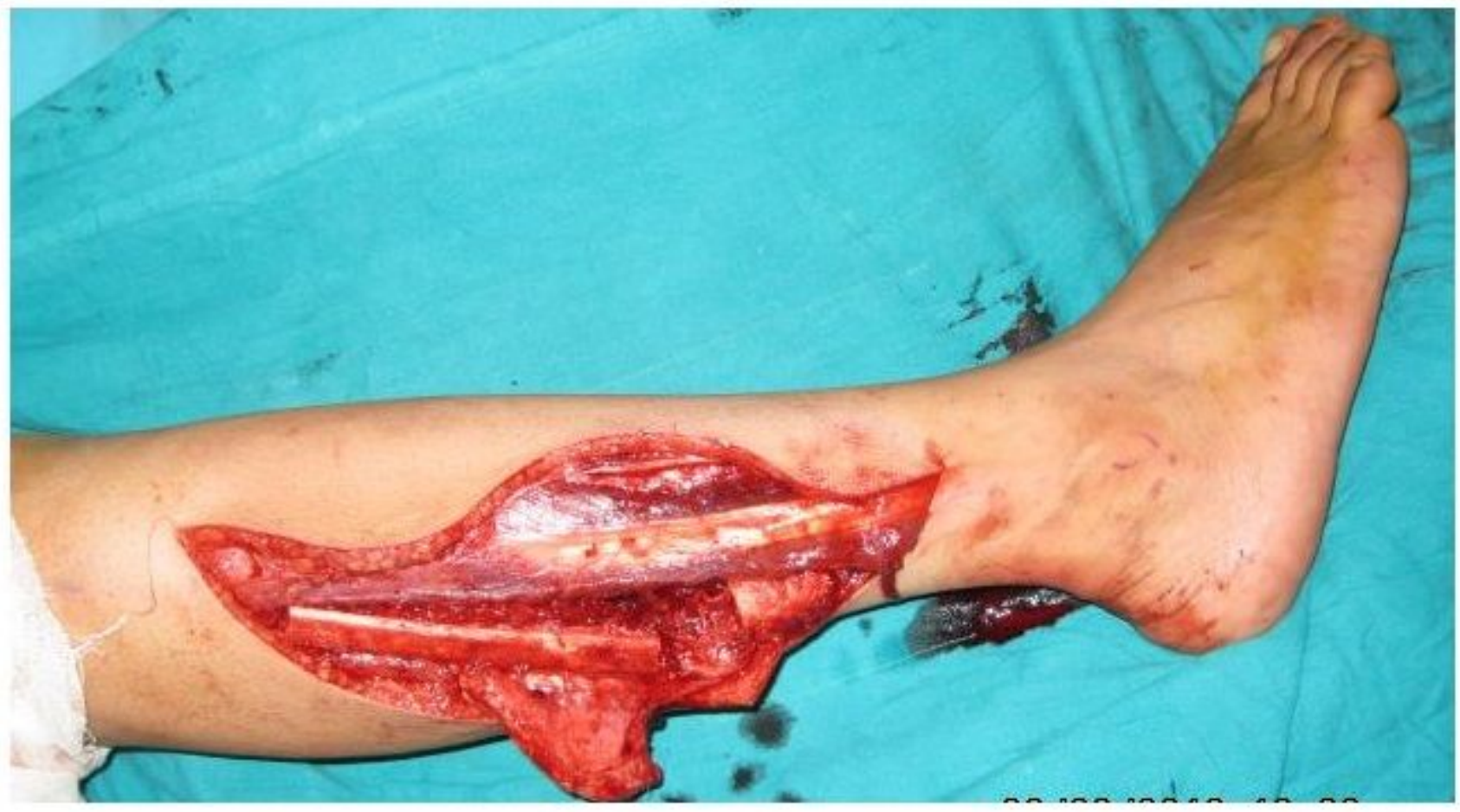

Figure 4 
The fibula harvested from the right leg. Two osteotomies have been performed and a bony segment removed in the middle to facilitate double barrelling.

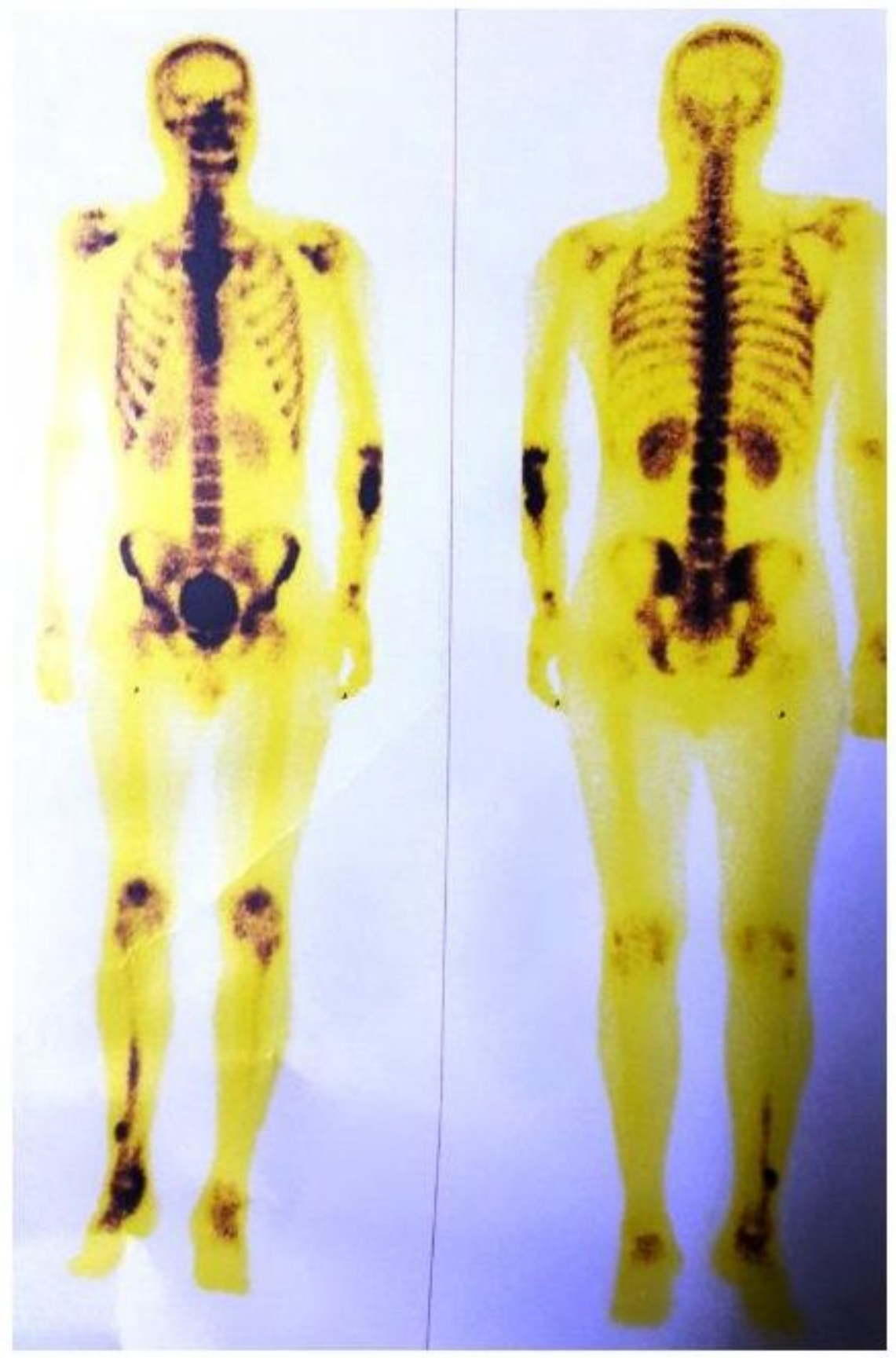

Figure 5

Whole body bone scan confirmed enhanced local blood supply. The scan was performed one year after surgery. 


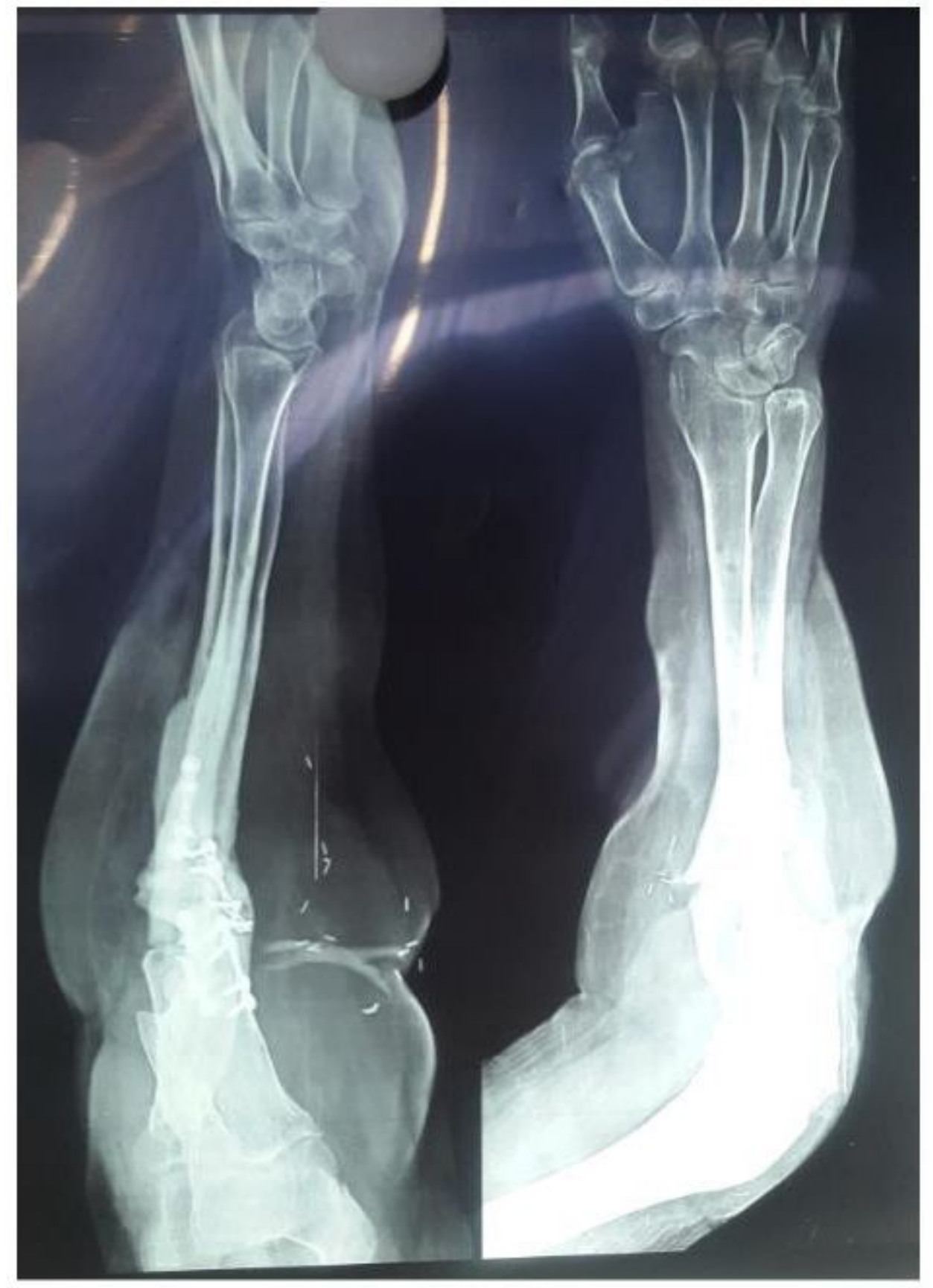

Figure 6

Xray of the proximal forearm showing bony union. The miniplates are in situ. 


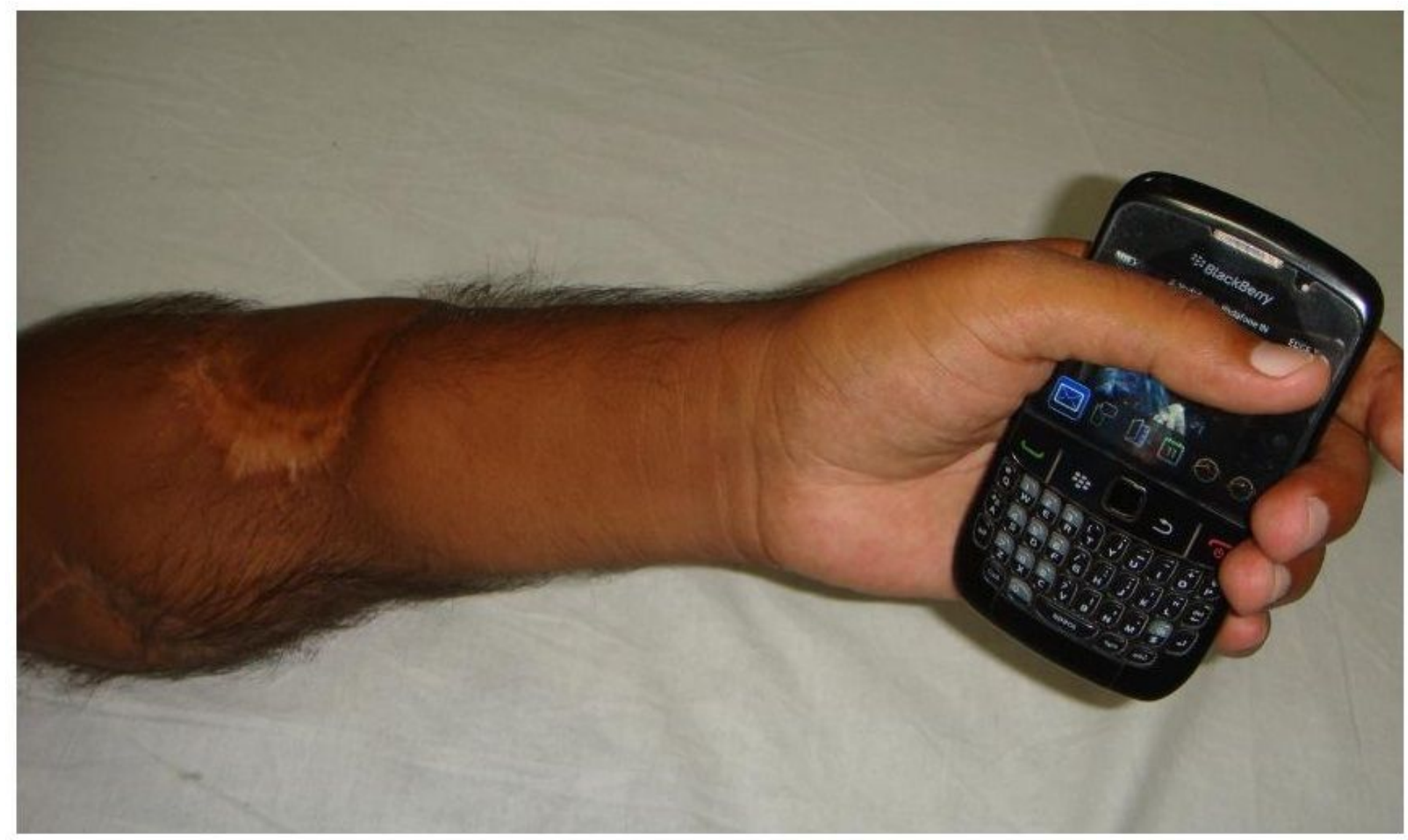

\section{Figure 7}

The patient uses his left hand for daily activities as an active supporting limb and for grasping small objects.

\section{Supplementary Files}

This is a list of supplementary files associated with this preprint. Click to download.

- CAREchecklistsupplementaryfile.pdf 